\title{
Does Creatine Supplementation Increase the Risk of Rhabdomyolysis?
}

The case report by Robinson ${ }^{1}$ in this issue of The fournal represents the most serious published report to date of an adverse effect in a person taking oral creatine supplements. In light of its severity, it is prudent to speculate on the likelihood that this man's creatine consumption contributed to his rhabdomyolysis.

Rhabdomyolysis results from a breakdown of the muscle cell wall, which leads to cell necrosis. It is thought to be the result of a plasma membrane defect or a disturbance in the sodium-potassium pump that allows an influx of calcium into the cell, which triggers a cascade of events leading to cell necrosis. ${ }^{2}$ Robinson speculates that intracellular water retention led to increased skeletal muscle compartment pressures, which placed the patient at risk for cellular wall breakdown.

Such a hypothesis is simplistic yet worthy of consideration. It is accepted that oral creatine supplementation results in a rapid weight gain, easily noted within 24 hours. ${ }^{3,4}$ Clearly, 24 hours is not enough to induce skeletal muscle hypertrophy; the gain is the result of intracellular and extracellular fluid retention. Although no studies have evaluated creatine supplementation and its effect on muscle compartment pressures, anecdotal evidence of athletes feeling "tight" or "cramped" abounds. Muscle cramping remains one of the most common side effects reported by those taking creatine. ${ }^{5,6}$

Risk factors for rhabdomyolysis include dehydration, alcoholism, illicit drug use, trauma, strenuous exercise, hypophosphatemia, and a hyperosmolal state. ${ }^{2,7,8}$ Robinson's patient had exercised the day before Robinson saw him, though his fluid and electrolyte status were not known. It has been hypothesized that creatine supplementation increases the risk of dehydration from intravascular volume depletion. Even creatine manufacturers

Submitted 5 November 1999.

From the Hall Health Primary Care Center, Family Medicine and Sports Medicine Clinics, University of Washington, Seattle. Address reprint requests to Mark S. Juhn, DO, Hall Health Primary Care Center, Family Medicine and Sports Medicine Clinics, University of Washington, Box 354410, Seattle, WA 98195-4410. recommend a healthy fluid intake while on creatine supplements.

Rhabdomyolysis has been reported in athletes who were not taking creatine supplements. There are factors, however, that suggest creatine was at least a contributing factor. First, as do many athletes who believe more is better, this patient was taking a very high dose for an extended time. Such high doses and long periods are not only contrary to recommendations, but they are also unstudied. Second, he was previously healthy and had been body building for 5 years; only during the last year was he taking creatine supplements. Third, he was not taking any other supplement that could be a contributing factor.

Advocates of creatine supplementation often state there is no direct evidence of a causal relation between oral creatine supplementation and any adverse side effect. Such a statement is often misinterpreted as proof that creatine is safe. Establishing a statistically significant relation, however, between a catastrophic event such as rhabdomyolysis and any type of supplement is unrealistic, particularly when using human subjects.

As clinicians, we need to evaluate such cases by incorporating a balance between healthy skepticism and open-mindedness. Given the metabolic and physiologic changes that occur with oral creatine supplementation, combined with the excessive dosing, Robinson's case adds support to the hypothesis that the use of oral creatine supplements can lead to serious adverse effects. More importantly, it brings to mind the question that has been plaguing many for years about the role of ergogenic aids for sport: Is it really worth it?

$$
\begin{array}{r}
\text { Mark S. Juhn, DO } \\
\text { Seattle }
\end{array}
$$

\section{References}

1. Robinson SJ. Acute quadriceps compartment syndrome and rhabdomyolysis in a weight lifter using high-dose creatine supplementation. J Am Board Fam Pract 2000;13:134-7.

2. Poels PJ, Gabreels FJ. Rhabdomyolysis: a review of the literature. Clin Neurol Neurosurg 1993;95:17592.

3. Hultman E, Soderlund K, Timmons JA, Cederblad 
G, Greenhaff PL. Muscle creatine loading in men. J Appl Physiol 1996;81:232-7.

4. Vandenberghe $K$, Goris $M$, Van Hecke $P$, Van Leemputte $M$, Vangerven L, Hespel P. Long-term creatine intake is beneficial to muscle performance during resistance training. J Appl Physiol 1997;83:2055-63.

5. Juhn MS, O'Kane JW, Vinci DM. Oral creatine supplementation in male collegiate athletes: a survey of dosing habits and side effects. J Am Diet Assoc 1999;5:593-5.
6. LaBotz M, Smith BW. Creatine supplement use in an NCAA Division I athletic program. Clin J Sport Med 1999;9:167-9.

7. Knochel JP. Mechanisms of rhabdomyolysis. Curr Opin Rheumatol 1993;5:725-31.

8. Singhal PC, Kumar A, Desroches L, Gibbons N, Mattana J. Prevalence and predictors of rhabdomyolysis in patients with hypophosphatemia. Am J Med 1992;92:458-64. 